\title{
Assessment of the trabeculated to compacted layer ratio of the left ventricle using short and longitudinal axis views in young patients presenting with ventricular dysrhythmias
}

\author{
Moneal Shah ${ }^{1 *}$, Lynette Duncanson ${ }^{2}$, Ellen Cummings ${ }^{2}$, Jie J Cao ${ }^{2}$ \\ From 16th Annual SCMR Scientific Sessions \\ San Francisco, CA, USA. 31 January - 3 February 2013
}

\section{Background}

Cardiac MRI (CMR) is increasingly being used clinically to assess the regional thickness of the compacted and trabeculated layers of the left ventricle (LV) in patients with suspected non-compaction. However, there is no consensus on whether the short or longitudinal axis view is preferred. We sought to assess the compacted and trabeculated layers in a young ventricular dysrhythmia population with age matched controls and to compare the measurements derived from both the short axis and longitudinal views.

\section{Methods}

The study consisted of 91 patients aged 20 to 49 years with ventricular dysrhythmia (VT) and 23 age-matched normal subjects. Regional wall thickness was assessed in short axis CMR cine views using a basal, mid and apical slice as well as in longitudinal views using the 2, 3, and 4 chamber view. The images were analyzed at end-diastole where the compacted layer was measured following the standardized 16-segment model. The apical segments were chosen $2 \mathrm{~cm}$ from the most apical portion of the LV for both short and longitudinal views. Within each wall segment, the most prominent trabeculation was measured, and the ratio of the trabeculated to compacted layer was compared between the VT group and controls in both views.

\section{Results}

The mean age was 38 years and 48 (42\%) were men. In the VT group, 31 had premature ventricular contractions and 60 had ventricular tachycardia. VT patients were associated with larger LV end-diastolic volumes $(89.7 \mathrm{ml} /$ $\mathrm{m} 2$ vs. $82.6 \mathrm{ml} / \mathrm{m} 2, \mathrm{p}=0.05)$, larger $\mathrm{LV}$ mass $(58 \mathrm{~g} / \mathrm{m} 2 \mathrm{vs}$. $49.9 \mathrm{~g} / \mathrm{m} 2 \mathrm{p}=0.001)$, and lower LV ejection fraction (50\% vs. $60 \% \mathrm{p}=0.015)$ as compared to the control group, respectively. Using the short axis view, the prevalence of trabeculated to compacted layer ratios $\geq 2.0, \geq 2.1, \geq 2.2$ and $\geq 2.3$ were $18.4 \%, 15.2 \%, 9.2 \%$ and $8.7 \%$ in the VT group, respectively while the prevalence in the control group was $13 \%$ for a ratio $\geq 2.0$ with no segments $\geq 2.1$. Using the same ratio cut points for the longitudinal view, the prevalence was $39.1 \%, 32.6 \%, 27.2 \%$ and $16.3 \%$ in the VT group and $43 \%, 39.1 \%, 21.7 \%$, and $13 \%$ in controls, respectively.

\section{Conclusions}

In this young cohort, the trabeculated to compacted ratio $\geq 2.1$ is only present in patients with ventricular dysrhythmias and not seen in normal controls using short axis planes, suggesting that increased thickness of the trabeculated layer in young subjects may be associated with the risk of ventricular dysrhythmia. However, the ratio $\geq 2.3$ is equally prevalent in both groups using longitudinal planes. Our findings suggest that the short axis view may be more discriminatory then the longitudinal view in identifying normal subjects. More importantly, there is a clear need to standardize the assessment of the trabeculated to compacted layer ratio in clinical practice.

\section{Funding}

None.

1Allegheny General Hospital, Pittsburgh, PA, USA

Full list of author information is available at the end of the article

(C) 2013 Shah et al; licensee BioMed Central Ltd. This is an Open Access article distributed under the terms of the Creative Commons Attribution License (http://creativecommons.org/licenses/by/2.0), which permits unrestricted use, distribution, and reproduction in any medium, provided the original work is properly cited. 


\section{Author details}

${ }^{1}$ Allegheny General Hospital, Pittsburgh, PA, USA. ${ }^{2}$ Cardiology, St. Francis Hospital, Rosyln, NY, USA.

Published: 30 January 2013

doi:10.1186/1532-429X-15-S1-P62

Cite this article as: Shah et al:: Assessment of the trabeculated to compacted layer ratio of the left ventricle using short and longitudinal axis views in young patients presenting with ventricular dysrhythmias. Journal of Cardiovascular Magnetic Resonance 2013 15(Suppl 1):P62.

Submit your next manuscript to BioMed Central and take full advantage of:

- Convenient online submission

- Thorough peer review

- No space constraints or color figure charges

- Immediate publication on acceptance

- Inclusion in PubMed, CAS, Scopus and Google Scholar

- Research which is freely available for redistribution

Submit your manuscript at www.biomedcentral.com/submit
() Biomed Central 